\title{
PENERAPAN MESIN PRODUKSI KAYU MULTI FUNGSI UNTUK MENINGKATKAN PRODUKTIVITAS UMKM MEBEL KOTA KUPANG
}

\author{
Nursalim $^{1, *}$, Agusthinus S. Sampeallo ${ }^{2}$, Abdul Wahid ${ }^{3}$, Nixson J. Meok ${ }^{4}$ \\ ${ }^{1,2}$ Program Studi Teknik Elektro, Fakultas Sains dan Teknik, Universitas Nusa Cendana \\ ${ }^{3}$ Program Studi Fisika, Fakultas Sains dan Teknik, Universitas Nusa Cendana \\ ${ }^{4}$ Program Studi Teknik Elektro, PTK FKIP, Universitas Nusa Cendana \\ Kupang-NTT, Telp. 085239065458 \\ Email Korespondensi : *nursalim@staf.undana.ac.id
}

Received : October 28, 2020 ; Accepted : November 30 , 2020 ; Published : January 1 ${ }^{\text {st }}, 2021$

\begin{abstract}
Abstrak
Pola hidup masyarakat NTT yang semakin modern membuat peluang usaha mebel seperti mebel UD. Gusti Karya semakin lebih terbuka lebar. Karena semakin modernnya pola hidup masyarakat, maka gaya hidup akan semakin konsumtif, mewah, individualis, dan serba instan. UD. Gusti Karya adalah merupakan mitra dari program PPPUD yang berlokasi di jalan bajawa kota kupang. Usaha ini telah dimulai sejak tahun 1997. Namun semakin bertambahnya hari, omzet yang dihasilkan semakin menurun. Hal ini disebabkan karena keterbatasan peralatan yang dimiliknya, sehingga jumlah produk yang mereka hasilkan sangat terbatas. Program ini bertujuan untuk memberikan solusi terhadap permasalahan yang sedang dihadapi oleh mitra terkait dengan masalah peningkatan produksinya. Solusi yang ditawarkan yaitu dengan melakukan penerapan mesin produksi kayu multi fungsi. Karena menurut mitra, semenjak usahanya dimulai, mitra belum pernah melakukan peremajaan peralatan, apalagi menggunakan mesin produksi kayu dengan teknologi yang lebih modern. Masalah ini kemudian mengakibatkan proses produksi menjadi sangat lamban sehingga menyebabkan produktivitas semakin menurun. Hasil evaluasi kegiatan menunjukkan bahwa, dengan menerapkan mesin produksi kayu multi fungsi pada program PPPUD ini, maka proses produksi mitra mengalami peningkatan sesuai dengan tujuan dari program ini.
\end{abstract}

Kata Kunci: usaha mikro, mebeler kota kupang, mesin mebeler multi fungsi

\section{Abstract}

The lifestyle of the people of NTT which is increasingly modern creates opportunities for furniture business such as UD furniture. Gusti Karya is more and more open. Due to the increasingly modern lifestyle of society, the lifestyle will be more consumptive, luxurious, individualistic, and instantaneous. UD. Gusti Karya is a partner of the PPPUD program located on Jalan Bajawa, Kupang City. This business has been started since 1997. However, the increasing number of days, the resulting turnover has decreased. This is due to the limited equipment they have, so the number of products they produce is very limited. This program aims to provide solutions to problems currently being faced by partners related to the problem of increasing their production. The solution offered is to implement a multifunctional wood production machine. Because according to the partner, since the business began, the partner has never renovated any equipment, let alone used a wood production machine with more modern technology. This problem then causes the production process to be very slow, causing productivity to decrease. The results of the activity evaluation show that, by implementing a multi-functional wood production machine in this PPPUD program, the partner's production process has increased according to the objectives of this program. 
Keywords: micro-business, furniture in Kupang city, multi-function furniture machines

\section{Pendahuluan}

Kota Kupang adalah sebuah kotamadya dan sekaligus ibu kota provinsi Nusa Tenggara Timur, Indonesia. Kotamadya ini adalah kota yang terbesar di Pulau Timor yang terletak di pesisir Teluk Kupang, bagian barat laut pulau Timor. Saat ini jumlah penduduk kota kupang adalah sebanyak 434972 dari total jumlah penduduk provinsi Nusa Tenggara Timur (NTT) yang sebesar 5,456.203 [1]. Tentu saja, sebagai kota madya dan sekaligus ibu kota pasti membutuhkan berbagai fasilitas pendukung seperti ketersediaan sarana perumahan, rumah makan, penginapan atau hotel yang representatif, perkantoran, pendidikan dan kesehatan[2]. Hal ini dibuktikan dari data [1], dimana data tersebut memperlihatkan jumlah penambahan Hotel berbintang Menurut Klasifikasi di Kota Kupang 2015-2019 naik mencapai 50\%, Sedangkan Jumlah Rumah Makan dan Restoran di kelurahan oebobo naik mencapai $28 \%$.

Melihat pola hidup masyarakat NTT yang semakin modern, maka peluang usaha mebel akan semakin lebih terbuka lebar, karena semakin modernnya pola hidup masyarakat, maka gaya hidup akan semakin konsumtif, mewah, individualis, dan serba instan[3], [4]. Hal ini juga dibenarkan oleh sulur [5]. Menurutnya, saat ini Bahan mebel dari kayu jati saat ini makin diminati warga Kota Kupang, karena selain kuat, mebel dapat dibuat sesuai dengan selera konsumen. Sulur juga menambahkan bahwa, hampir seluruh produk mebel seperti untuk aksesoris rumah tangga atau instansi pemerintahan dan lembaga pendidikan dikerjakan dari bahan kayu jati. Bahkan hasil mebel yang dimilikinya mampu laku terjual hingga puluhan unit per bulannya. Hal ini menandakan bahwa kondisi ekonomi masyarakat NTT semakin mapan yang menyebabkan lahirnya masyarakat yang konsumtif [6].

UD. Gusti Karya adalah merupakan pelaku Usaha Mikro, Kecil, dan Menengah (UMKM) yang memproduksi mebeler di kota kupang yang telah berdiri sejak tahun 1997. UMKM ini adalah merupakan mitra Program Pengembangan Produk Unggulan Daerah (PPPUD) yang berlokasi di jalan Bajawa Kelurahan Oebobo Kota Kupang. Sejak memulai usahanya, hingga saat ini belum pernah sepi dari orderan pelanggan. Bahkan, produk mitra telah terkenal sampai di kota maumere yang ada di Pulau Flores. Namun, walaupun produknya telah terkenal, omzet yang dihasilkan semakin hari semakin menurun. Menurut mitra, salah satu faktor penyebabnya adalah karena peralatan yang digunakan sudah terbelakang, sehingga produktitivatasnya terbatas [7], [8]. Data produksi mitra menunjukkan, bahwa sebelum kegiatan ini berlangsung, produksi mitra hanya mampu menyelesaikan dan menghasilkan 105 jenis produk. Untuk itu, agar usaha mitra dapat berkembang dan memiliki daya saing yang tinggi, maka perlu diadakan sebuah program yang dapat membantu mitra untuk mengatasi persoalan yang sedang dihadapi.

Program ini bertujuan untuk memberikan solusi terhadap permasalahan yang sedang dihadapi oleh UD. Gusti Karya, terkait dengan peningkatan hasil produksinya[9]. Solusi yang diberikan yaitu melakukan peningkatan produksi dengan cara menerapkan mesin produksi kayu multi fungsi. Menurut mitra, semenjak usahanya berdiri, belum pernah memperbaharui peralatan yang digunakan karena disebabkan dana yang dimiliki terbatas. Sehingga untuk melanjutkan usahanya, mitra hanya bergantung pada peralatan manual yang dari sisi teknologi sudah tertinggal.

\section{Metode}

Metode yang digunakan dalam program ini adalah metode rancang bangun yang dilakukan dalam tiga tahap yaitu: (1) tahap persiapan, (2) tahap kegiatan, dan (3) tahap evaluasi [10], [11]. Selain metode rancang bangun, juga digunakan metode SWOT. Metode ini digunakan untuk mengalisis kondisi mitra pengabdian, agar kegiatan pengabdian bermanfaat bagi mitra. 
Analisis SWOT adalah metode perencanaan strategis yang digunakan untuk mengevaluasi kekuatan (strengths), kelemahan (weaknesses), peluang (opportunities), dan ancaman (threats) dalam suatu proyek atau suatu spekulasi bisnis. Keempat faktor itulah yang membentuk akronim SWOT (strengths, weaknesses, opportunities, dan threats) [12]. Setelah mendapatkan data kebutuhan mitra dengan metode SWOT, kemudian dilakukan perancangan dan pembuatan alat yang dibutuhkan oleh mitra. Setelah itu, peralatan yang telah dibuat kemudian diuji dan dievaluasi dengan tujuan untuk mengetahui sejauh mana alat ini dapat bekerja [13], [14].

\section{Hasil dan Pembahasan}

Untuk dapat metode rancang bangun, maka terlebih dahulu dilakukan analisis untuk melihat kondisi mitra PPPUD agar pelaksanaan kegiatan pengabdian bermanfaat bagi mitra dengan menggunakan SWOT. Kekuatan (Strength,) kayu Jati adalah merupakan jenis hasil hutan terbanyak kedua di Provinsi Nusa Tenggara Timur (NTT) setelah jenis hasil hutan Rimba Campuran. Data tentang statistik pertanian provinsi NTT menunjukkan bahwa produksi kayu jati pada tahun 2017 mencapai $1.986 .78 \mathrm{~m} 3$ [15]. Bagi mitra PPPUD, jenis kayu jati ini dapat menjadi peluang usaha, karena jenis kayu ini sangat disukai oleh masyarakat kota kupang, karena selain dapat dibuat sesuai selera konsumen, kayu jati juga merupakan merupakan jenis kayu yang kuat dan tahan terhadap jamur, rayap, dan serangga [16]. Kelemahan (Weakness), adanya keterbatasan dana menyebabkan mitra PPPUD ini hampir tidak pernah tersentuh oleh mesin produksi kayu yang memiliki teknologi baru. Sejak usahanya dimulai, mitra belum pernah melakukan peremajaan mesin, sehingga produktivitas mitra semakin hari semakin menurun. Akibatnya, omzet yang dihasilkan juga semakin menurun. Peluang (Opportunity), Sebagai ibu kota provinsi NTT dengan penduduk sebanyak 434.972, tentunya membutuhkan berbagai fasilitas pendukung seperti ketersediaan sarana perumahan, rumah makan, penginapan, hotel yang representatif, perkantoran, pendidikan dan kesehatan. Hal ini tentu saja menjadi peluang usaha bagi mitra dalam membuat berbagai macam jenis furniture. Apalagi ditambah dengan pengalaman mitra yang sudah menggeluti usaha ini sejak tahun 1997, tentunya menjadi peluang yang sangat besar untuk dapat bersaing di bidang ini. Namun, seiring dengan perkembangan kota kupang yang semakin pesat, tentu ancaman (Threat) dari pengusaha sejenis, pasti akan bertambah. Untuk itu, maka diperlukan suatu kegiatan atau program yang dapat membantu mitra PPPUD untuk tetap dapat bersaing dalam bidang usaha ini.

Setelah menganalisa permasalahan mitra menggunakan metode SWOT, kemudian diketahui bahwa untuk dapat meningkatkan produktivitasnya, diperlukan suatu mesin yang dapat mempercepat proses pekerjaanya. Berdasarkan hasil diskusi dengan mitra, maka disepakati penerapan teknologi mesin multi fungsi mengatasi permasalahan yang sedang dihadapi oleh mitra. Mesin multi fungsi yang disepakti terdiri dari mesin router, jigsaw dan circular saw. Ketiga mesin ini akan ditempatkan pada satu meja, sehingga efisiensi kerja dapat ditingkatkan. Adapun urutan pelaksanaan kegiatan ini adalah sebagai berikut.

\subsection{Perancangan Mesin Produksi Multi Fungsi}

Proses perancangan mesin multi fungsi ini diawali dengan pemilihan sumber inspirasi dan pencarian ide, pembuatan sketsa ide, pembuatan studi model mesin, dilanjutkan dengan pembuatan mesin multi fungsi. Ide mesin multi fungsi dikembangkan dari hasil diskusi dengan mitra, sehingga dimensi mesin disesuaikan dengan kebutuhan mitra. Dengan demikian, mesin multi fungsi yang dihasilkan memiliki inovasi yang sesuai dengan keinginan mitra, sehingga penggunaan mesin dapat menjadi lebih efektif dan lebih mudah. Adapun gambar perancangan dan pembuatan mesin produksi multi fungsi ini diperlihatkan pada gambar 1.

Volume 4, Nomor 1, Januari 2021 


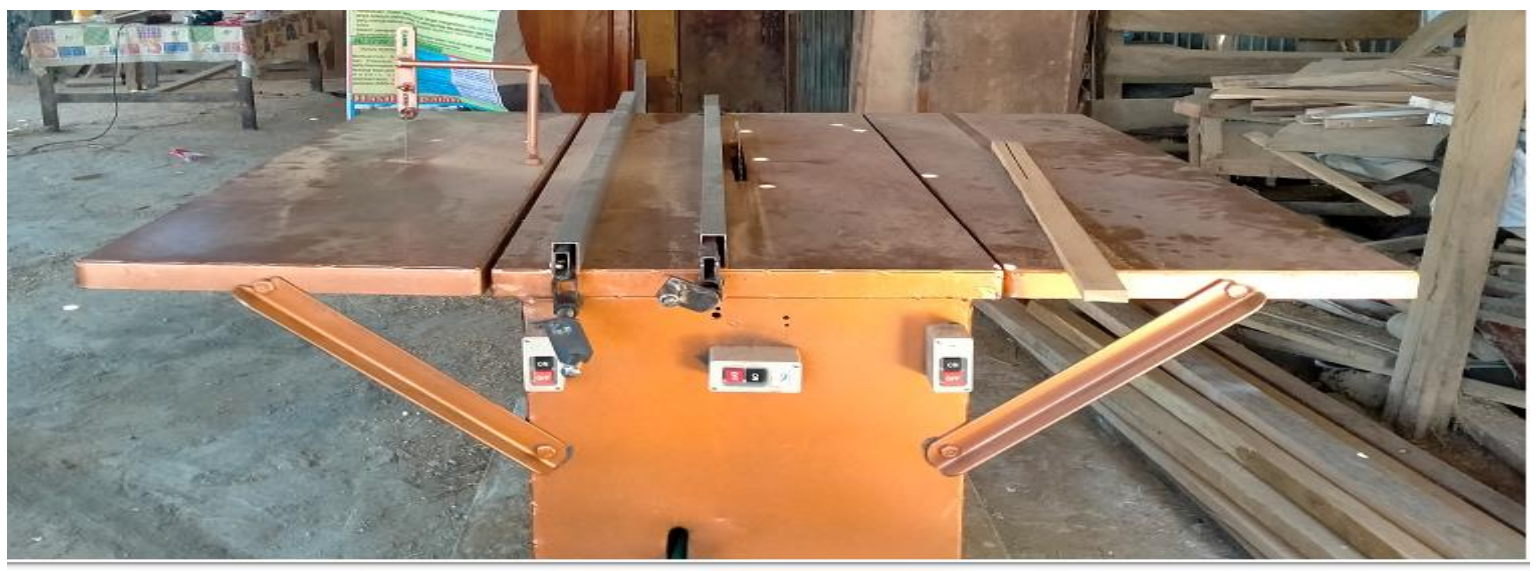

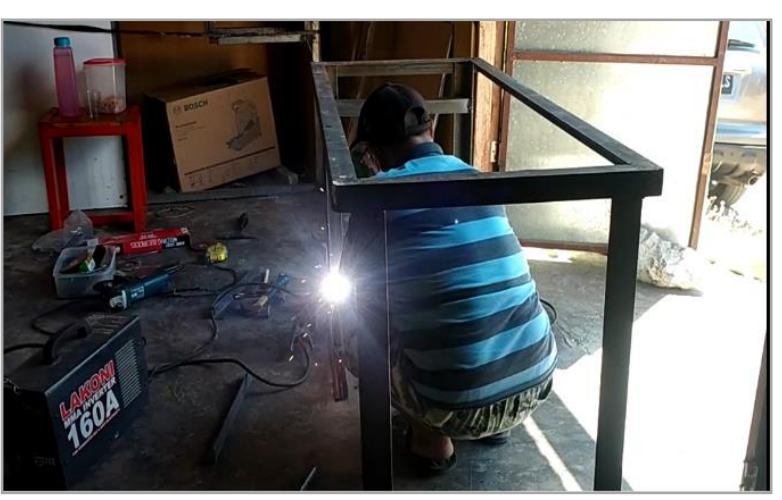

(a)

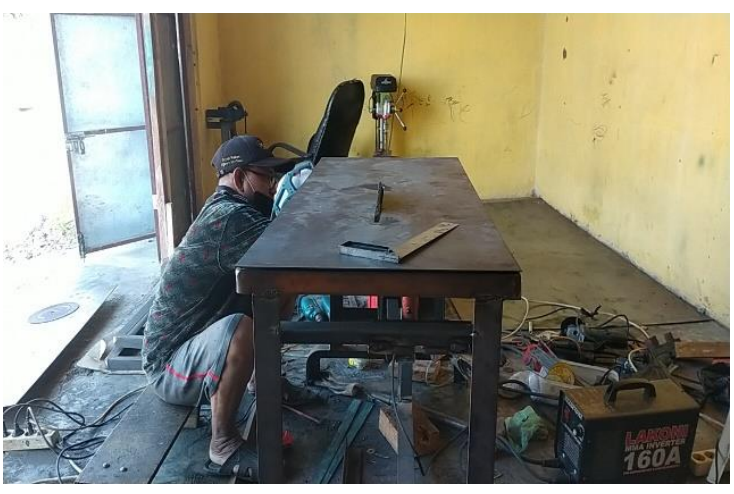

(b)

Gambar 1. Mesin Produksi Kayu Multi Fungsi (a) Perancangan rangka, (b) Perakitan mesin

\subsection{Pengujian Mesin Produksi Kayu Multi Fungsi}

Pada tahap ini, mesin diuji untuk mengetahui tingkat kemampuan dari mesin yang digunakan. Selain itu, pengujian ini juga dilakukan untuk melihat tingkat getaran dan kecocokan pemasangan bagian-bagian mesin, sehingga semua bagian dapat bekerja sesuai dengan yang diharapkan. Gambar pengujian peralatan yang diterapkan pada mitra dapat dilihat pada gambar 2 . 


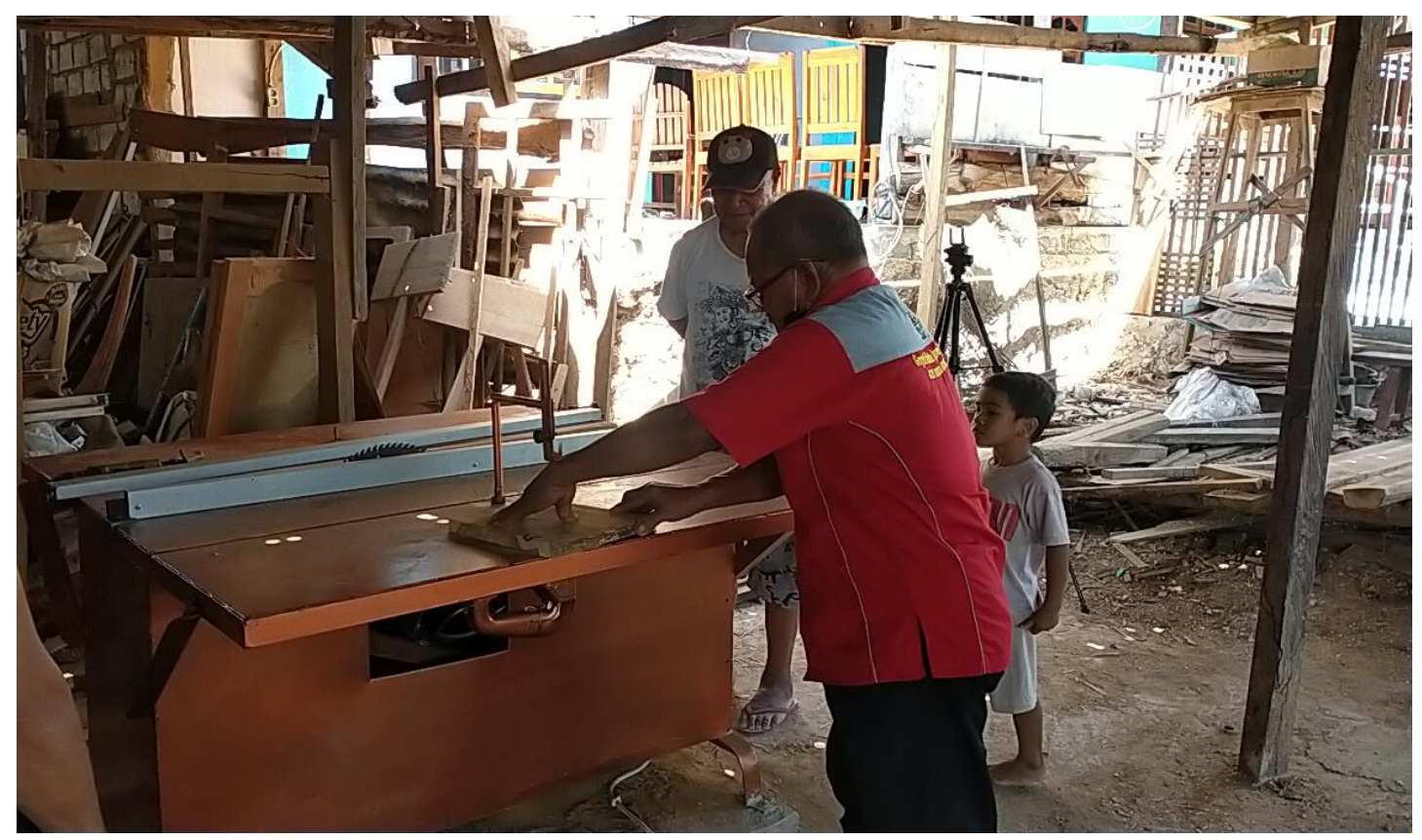

Gambar 2. Pengujian peralatan yang diterapkan pada mitra

Setelah memastikan mesin telah bekerja sesuai dengan diharapkan, maka langkah selanjutnya adalah melakukan evaluasi terhadap kinerja mesin, sehingga dapat diketahui peningkatan yang dicapai kegiatan ini.

\subsection{Evaluasi Hasil Kegiatan}

Evaluasi dilakukan dengan membandingkan jumlah hasil produksi mitra sebelum dan sesudah kegiatan ini berlangsung. Evaluasi ini mengambil data selama 1 tahun sebelum dan sesuah kegiatan berlangsung. Data sebelum kegiatan dimulai pada bulan oktober - September 2018 data setelah kegiatan dimulai pada bulan oktober - September 2019. Adapun hasil evaluasi yang dilakukan dapat dilihat pada Gambar 3.

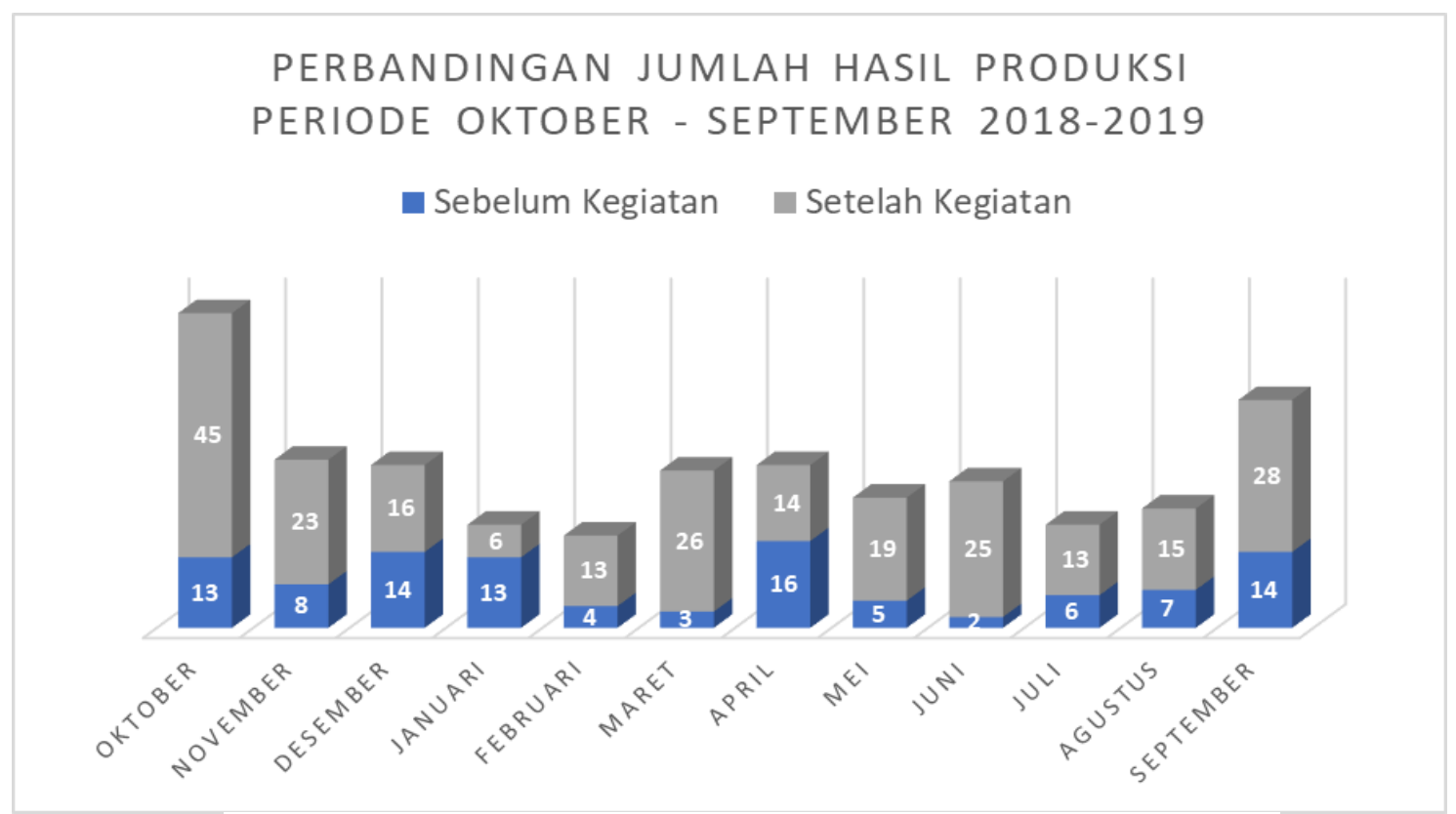

Gambar 3. Perbandingan jumlah hasil produksi UD. Gusti Karya 
Data Gambar 3 menunjukkan bahwa penerapan mesin produksi multi fungsi pada program PPPUD ini telah berhasil meningkatkan produktivitas usaha mitra. Peningkatan produktivitas terlihat sangat signifikan, dimana setelah kegiatan ini berlangsung, mitra mampu menghasilkan sebanyak 243 jenis produk. Hasil ini lebih banyak dibandingkan sebelumnya, dimana produk yang dihasilkan hanya mampu mencapai 105 jenis produk.

\section{Kesimpulan}

Setelah menerapkan mesin produksi kayu multi fungsi pada kegiatan PPPUD ini, kemudian dapat disimpulkan bahwa:

1. Program PPPUD ini telah dilaksanakan dengan capaian target sesuai dengan yang direncanakan yaitu adanya peningkatan produksi dibandingkan sebelum adanya kegiatan ini.

2. Dengan menggunakan analisa SWOT, dapat ditemukan titik permasalahan yang dihadapi mitra, sehingga memudahkan tim pelaksana untuk mengambil keputusan dalam menyelesaikan persoalan yang sedang dihadapi oleh mitra.

3. Hasil rancangan mesin produksi pada program ini telah dapat bekerja sesuai dengan ide dan keinginan mitra, sehingga hasil produksi dapat meningkat dibanding sebelumnya.

4. Jumlah produksi yang dihasilkan mampu mencapai 243 produk. Jumlah ini lebih banyak dibanding sebelumnya yang hanya mencapai 105 produk.

\section{Ucapan terima kasih}

Tim Pelaksana mengucapkan terima kasih kepada Ristek - BRIN (DRPM DIKTI) yang telah memberikan dana, sehingga pelaksanaan kegiatan ini dapat berjalan lancar sesuai dengan yang direncanakan. Selanjutnya tim Pelaksana juga mengucapkan terima kasih kepada Universitas Nusa Cendana khususnya Lembaga Penelitian dan Pengabdian Masyarakat (LP2M), yang senantiasa memantau dan memberi motivasi sehingga kegiatan ini dapat berjalan seperti yang diharapkan.

\section{Daftar pustaka}

[1] "BPS Kota Kupang," 2020. https://kupangkota.bps.go.id/publication/2020/04/27/2b60e73717878272a9433335/kotakupang-dalam-angka-2020.html (accessed Oct. 25, 2020).

[2] O. Mellolo, M. Langie, and E. M. Rongre, "IPTEKS Bagi Pengrajin Mebel Usaha Kecil Guna Meningkatkan Keterampilan Dan Hasil Produksi," no. 11, p. 7, 2016.

[3] N. L. Mufidah, "Pola Konsumsi Masyarakat Perkotaan: Studi Deskriptif Pemanfaatan Foodcourt oleh Keluarga," Biokultur, vol. 1, no. 2, pp. 157-178, 2006.

[4] Egindo.co, "Bentuk Dan Ciri-Ciri Gaya Hidup Masyarakat Modern," egindo.co, 2019. https://www.egindo.co/bentuk-dan-ciri-ciri-gaya-hidup-masyarakat-modern/ (accessed Oct. 25, 2020).

[5] POS KUPANG.COM, "Mebel Kayu Jati Diminati Warga Kupang," 2011. http://kupang.tribunnews.com/2011/06/23/mebel-kayu-jati-diminati-warga-kupang.

[6] O. Solihin, "Terpaan Iklan Mendorong Gaya Hidup Konsumtif Masyarakat Urban," no. 2, p. 10, 2015.

[7] Made Agus Putra Subali, I Gusti Rai Agung Sugiartha, and Arya Faisal Akbar, "Peningkatan Kuantitas dan Kualitas Produksi Kerupuk Basa di Desa Jegu, Kabupaten Tabanan," dinamisia, vol. 4, no. 4, Sep. 2020, doi: 10.31849/dinamisia.v4i4.4625.

[8] U. Nuha, S. Saroh, and D. Zunaida, "Pengaruh Bahan Baku, Proses Produksi Dan Pemeliharaan Peralatan Terhadap Kualitas Produk," vol. 9, no. 2, p. 6, 2020. 
[9] A. Pratama, Oktavima Wisdaningrum, and Magdalena Putri Nugrahani, "Pendampingan dan Penerapan Teknologi Untuk Peningkatan Produktivitas Usaha Mikro Gula Semut," dinamisia, vol. 4, no. 2, pp. 275-284, May 2020, doi: 10.31849/dinamisia.v4i2.3490.

[10] Alfian Saleh, Muthia Anggraini, and Sean Marta Efastri, "Penerapan Alat Permainan Edukatif Bertemakan Keselamatan Lalulintas Untuk Guru TK Karya Bunda Kec.Bandar Seikijang," dinamisia, vol. 4, no. 4, pp. 762-768, Sep. 2020, doi: 10.31849/dinamisia.v4i4.4911.

[11] A. Ardi, A. Rijanto, S. E. Kurniawan, and E. Aristyoardi, "Rancang Bangun Mesin Pemotong Balok Kayu Serbaguna Dengan Sistem Kontrol Otomatis," vol. 1, p. 11, 2019.

[12] A. H. Subarjo, B. Mardwianta, and T. Wibowo, "Peningkatan Pengetahuan Pemanfaatan Energi Matahari Untuk Mendukung Ketahanan Energi Pada Kelompok Pemuda Di Sendangtirto Berbah Sleman," KACANEGARA, vol. 3, no. 2, Jul. 2020, doi: 10.28989/kacanegara.v3i2.548.

[13] D. S. Iriani and S. Soeharto, "Evaluasi Pelaksanaan Praktik Kerja Industri Siswa Kompetensi Keahlian Jasa Boga SMK N 3 Purworejo," Jurnal Pendidikan Teknologi dan Kejuruan, vol. 22, no. 3, p. 274, Nov. 2015, doi: 10.21831/jptk.v22i3.6835.

[14] A. Rahayu, "Evaluasi Efektivitas Mesin Kiln dengan Penerapan Total Productive Maintenance pada Pabrik II/III PT Semen Padang," j.optim.sist.ind., vol. 13, no. 1, p. 454, Apr. 2016, doi: 10.25077/josi.v13.n1.p454-485.2014.

[15] N. Nursalim, A. S. Sampeallo, A. Wahid, and N. J. Meok, "Upaya Peningkatan Produksi Mebel Pada Umkm Kota Kupang Berbasis Teknologi Tepat Guna," Dinamisia: Jurnal Pengabdian Kepada Masyarakat, vol. 3, no. 2, Art. no. 2, Dec. 2019, doi: 10.31849/dinamisia.v3i2.3681.

[16] E. Hunggurami, S. Utomo, and B. Y. Messakh, "Identifikasi Kuat Acuan Terhadap Jenis Kayu yang Diperdagangkan di Kota Kupang Berdasarkan SNI 7973: 2013," Jurnal Teknik Sipil, vol. 5, no. 2, pp. 175-184, 2016.

[17] F. A. E. Sompie, F. J. Manoppo, and O. B. A. Sompie, "Stabilisasi Tanah Ekspansif Dengan Campuran Abu Batu Bara Dan Abu Terbang Batu Karang Dengan Aplikasi Timbunan Tipe Urugan Tanah,”p. 16, 2018. 
Nursalim, Agusthinus S. Sampeallo, Abdul Wahid, Nixson J. Meok 